\title{
PROFIL BEBAN PADA SISTEM KELISTRIKAN UNIVERSITAS BANGKA BELITUNG
}

\author{
Wahri Sunanda \\ Jurusan Teknik Elektro Universitas Bangka Belitung \\ e-mail: wahrisunanda@ubb.ac.id
}

\begin{abstract}
University of Bangka Belitung is currently supplied by PLN Bangka Belitung region with 690 kVA power supply to meet the need of electric energy on campus with total land 153 ha. Through direct measurements on the panels of each building, it is found that the use of power in the morning is higher than the use of power in the afternoon. Total power (3 phases) in the morning ie $194.6425 \mathrm{~kW}$, while in the afternoon $154,0396 \mathrm{~kW}$.
\end{abstract}

Keywords: 3 phases, electrical energy, power

\section{INTISARI}

Universitas Bangka Belitung saat ini dipasok oleh PLN Wilayah Bangka Belitung dengan pasokan daya 690 kVA untuk memenuhi kebutuhan energi listrik pada kampus dengan total lahan 153 ha. Melalui pengukuran langsung pada panel masing-masing gedung, didapat bahwa penggunaan daya pada pagi hari lebih tinggi jika dibandingkan penggunaan daya pada sore hari. Total daya (3 fase) pada pagi hari yakni 194,6425 kW, sedangkan pada sore hari 154,0396 kW.

Kata Kunci : 3 Fase, energi listrik, daya

\section{PENDAHULUAN}

Universitas Bangka Belitung (UBB) merupakan perguruan tinggi negeri yang ada di Provinsi Kepulauan Bangka Belitung. Berdiri pada 12 April 2006 dengan saat ini terdiri atas 19 Program Studi dan 5 Fakultas. Sebagai institusi pendidikan dengan jumlah total mahasiswa mencapai 5000 orang dengan didukung oleh tenaga pendidik dan tenaga kependidikan berjumlah 400 orang, tentunya menjadikan kebutuhan energi listrik pada setiap aktivitas menjadi penting.

UBB saat ini dipasok oleh PLN Wilayah Bangka Belitung dengan pasokan daya $690 \mathrm{kVA}$ untuk memenuhi kebutuhan energi listrik pada kampus dengan total lahan 153 ha ini. Walaupun penerangan jalan umum dipasok oleh PLTS, namun pasokan daya dari PLN merupakan hal yang utama. Oleh karenanya dalam kaitan ini, perlu dilihat dengan baik, pola penggunaan energi listrik melalui profil beban pada setiap gedung di lingkungan UBB.

\section{DASAR TEORI}

Dalam keadaan ajeg (steady state), arus dan tegangan sistem tenaga semuanya merupakan fungsi sinusoidal terhadap waktu dengan frekuensi yang sama. Oleh karena itu amat menarik apabila analisis keadaan ajeg dari sistem tenaga tersebut mempergunakan phasor, impedans, admitans dan daya kompleks. daya sesaat dinyatakan oleh

$$
p(t)=v(t) i(t)
$$

Diandaikan bahwa tegangan dan arus, keduanya dinyatakan oleh gelombang sinusoidal dengan kecepatan sudut $\omega$, dituliskan dengan pernyataan berikut:

$$
\begin{aligned}
& V(t)=V_{\max } \cos \left(\omega t+\theta_{v}\right) \\
& I(t)=I \max \cos \left(\omega t+\theta_{i}\right)
\end{aligned}
$$

dengan :

Vmax $=$ besaran nyata dari amplitudo tegangan

Imax = besaran nyata dari amplitudo arus

$\theta v=$ sudut fasa dari tegangan $(\angle V)$

$\theta i=$ sudut fasa dari arus $(\angle I)$ 
Berdasarkan persamaan (2.2) dan persamaan (2.3) akan diperoleh daya sebagai berikut:

$$
p(t)=V \max \cdot \operatorname{Imax} \cos (\omega t+\theta v) \cos (\omega t+\theta i)
$$

Untuk menghitung nilai sesaat daya tiga fasa digunakan persamaan berikut:

$$
P_{3}(t)=V_{a}(t) I_{a}(t)+V_{b}(t) I_{b}(t)+V_{c}(t) I_{c}(t)
$$

\section{METODE PENELITIAN}

Langkah penelitian yang dilakukan sebagai berikut :

1. Persiapan alat dan bahan penelitian, diantaranya; Power Quality Analyzer, kapasitas dan lokasi trafo distribusi, MCCB panel pada tiap gedung, diagram segaris sistem kelistrikan Universitas Bangka Belitung.

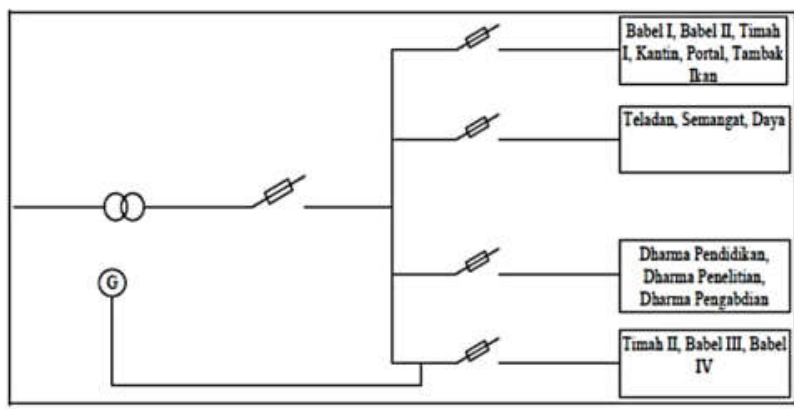

Gambar 1. Diagram segaris

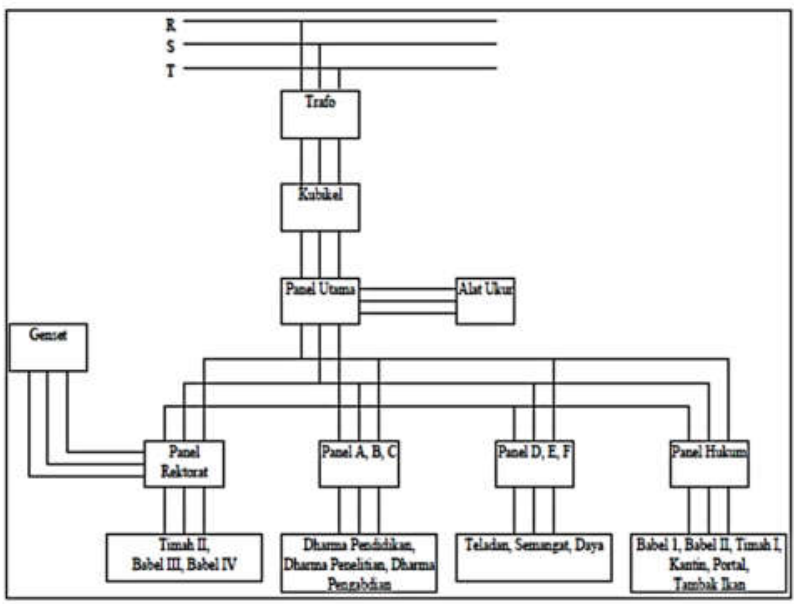

Gambar 2. Diagram pengawatan

2. Pengukuran $V$ dan I pada trafo distribusi (1250 kVA, $50 \mathrm{~Hz}, 3 \phi, 20 \mathrm{kV} / 400$ volt) dan panel pada tiap gedung.

\section{HASIL DAN PEMBAHASAN}

Pengukuran dilakukan pada tiap fase di trafo distribusi dan panel pada tiap gedung. Satu hari dilakukan pengukuran dua kali, pagi dan sore hari. Diasumsikan bahwa tingginya penggunaan hanya pada pagi (pukul 10.30 WIB) dan sore hari (pukul 14.30 WIB). Sedangkan untuk malam harinya, energi listrik hanya digunakan untuk penerangan, sehingga tidak bisa mendeskripsikan profil beban di Universitas Bangka Belitung.

\section{A. Pengukuran pada Trafo Distribusi}

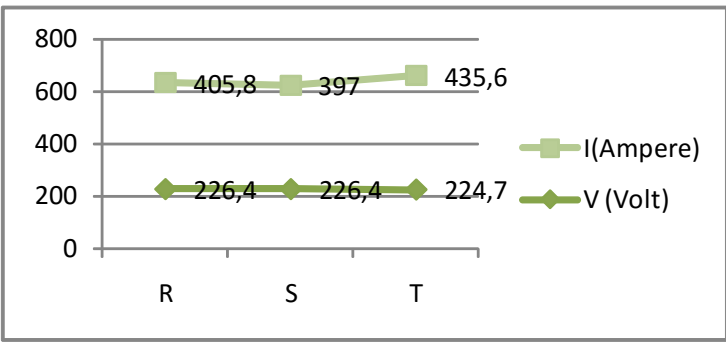

Gambar 3. Pengukuran pada pagi hari

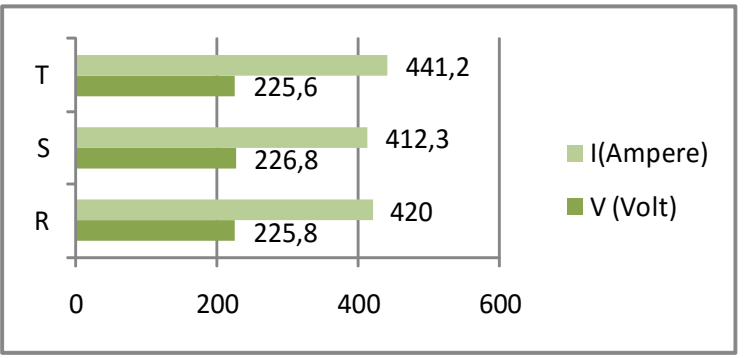

Gambar 4. Pengukuran pada sore hari

\section{B. Pengukuran pada Gedung Babel I}

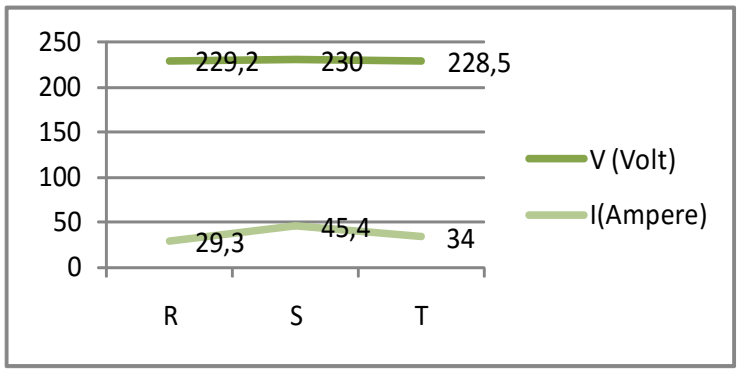

Gambar 5. Pengukuran pada pagi hari 


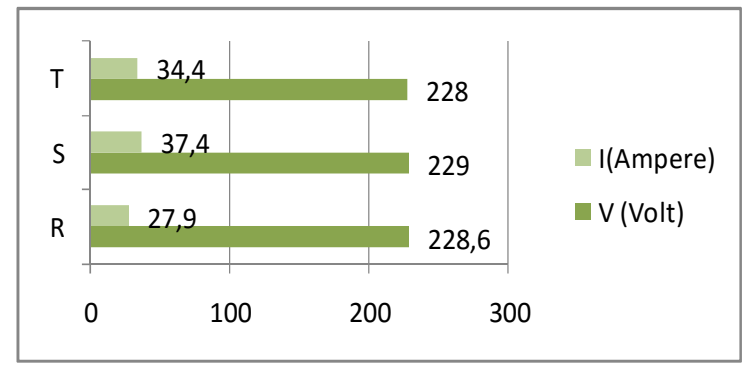

Gambar 6. Pengukuran pada sore hari

\section{Pengukuran pada Gedung Babel II}

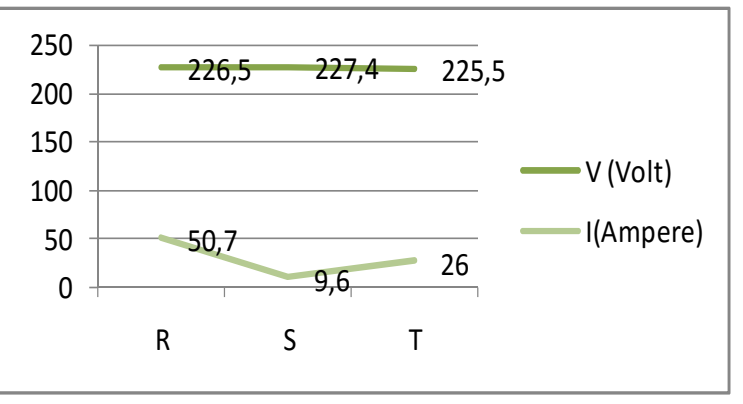

Gambar 7. Pengukuran pada pagi hari

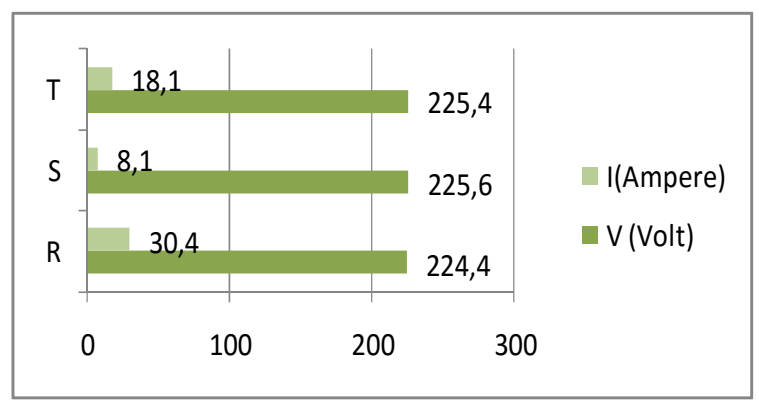

Gambar 8. Pengukuran pada sore hari

\section{Pengukuran pada Gedung Timah I}

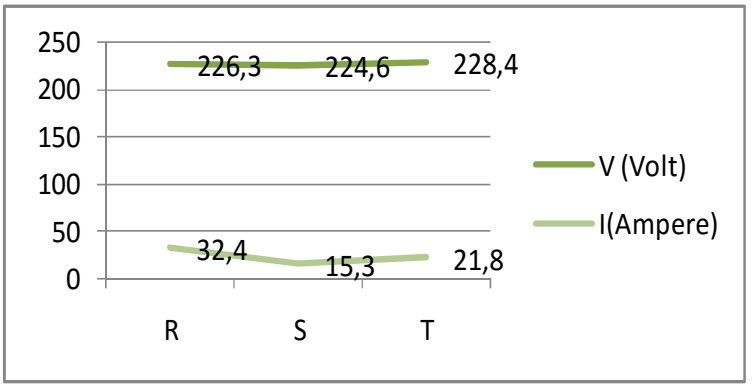

Gambar 9. Pengukuran pada pagi hari

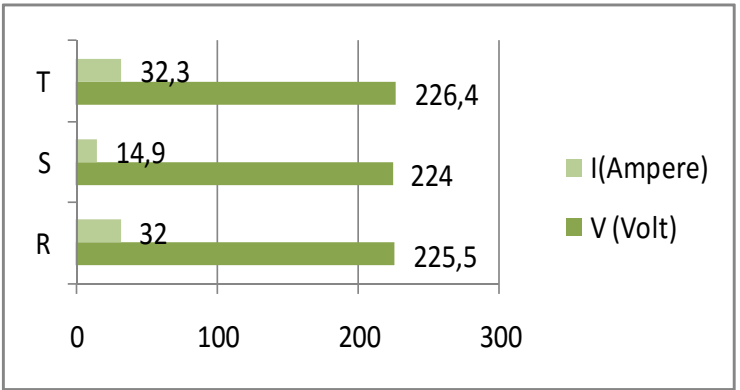

Gambar 10. Pengukuran pada sore hari

\section{E. Pengukuran pada Gedung Timah II}

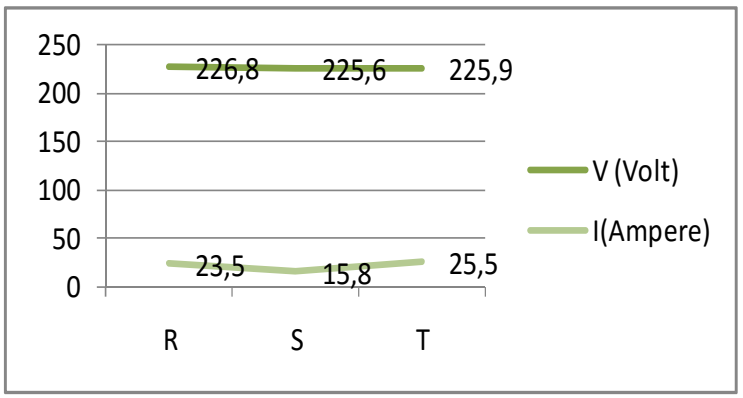

Gambar 11. Pengukuran pada pagi hari

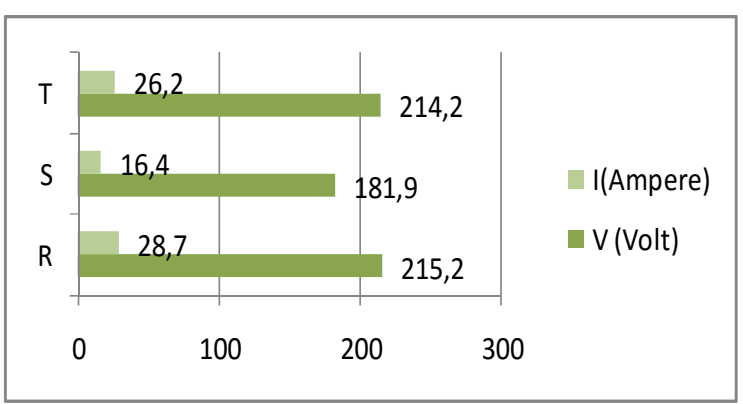

Gambar 12. Pengukuran pada sore hari

F. Pengukuran pada Gedung Babel III

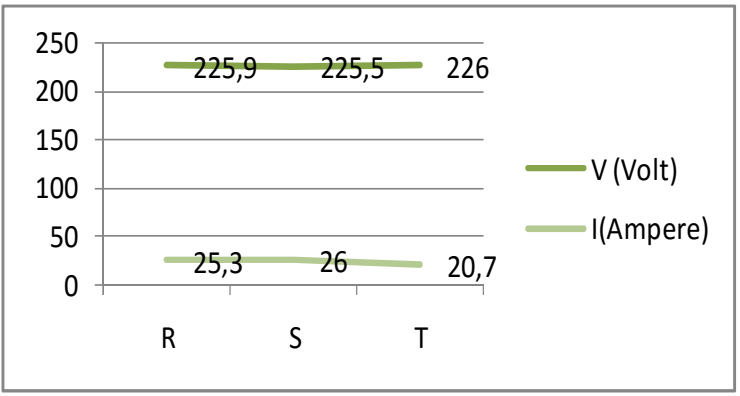

Gambar 13. Pengukuran pada pagi hari 


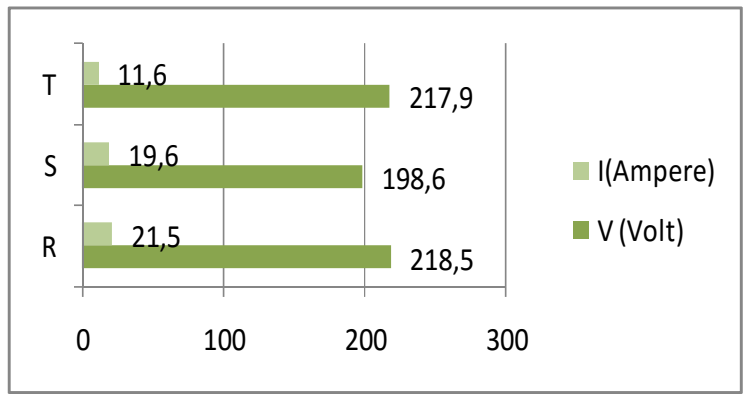

Gambar 14. Pengukuran pada sore hari

\section{G. Pengukuran pada Gedung Babel IV}

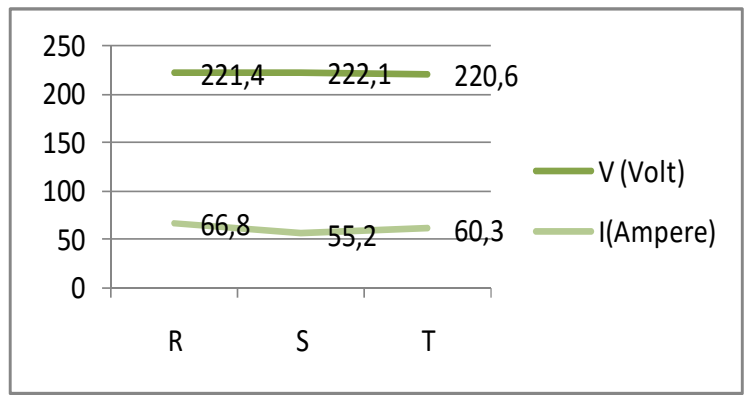

Gambar 15. Pengukuran pada pagi hari

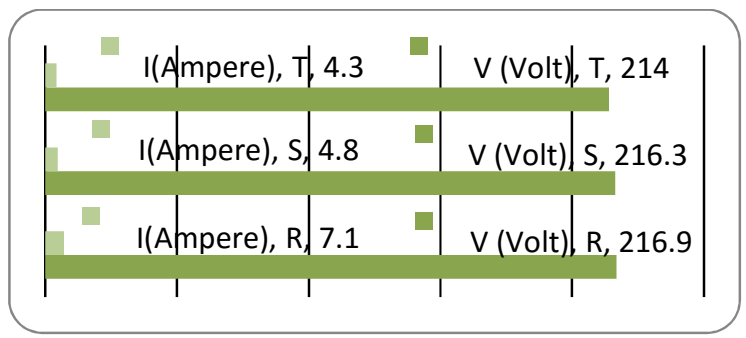

Gambar 16. Pengukuran pada sore hari

\section{H. Pengukuran pada Gedung Dharma} Pendidikan

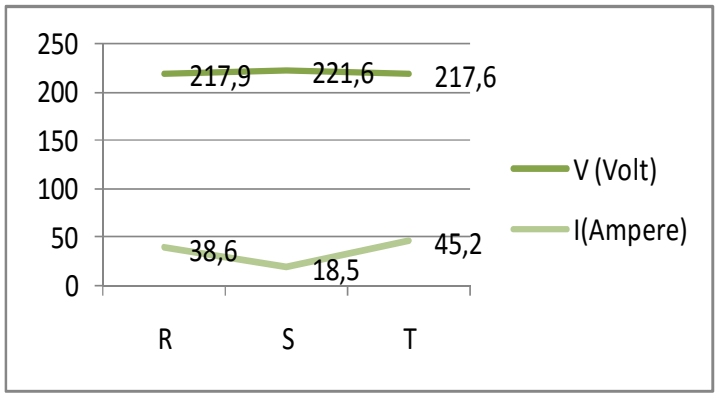

Gambar 17. Pengukuran pada pagi hari

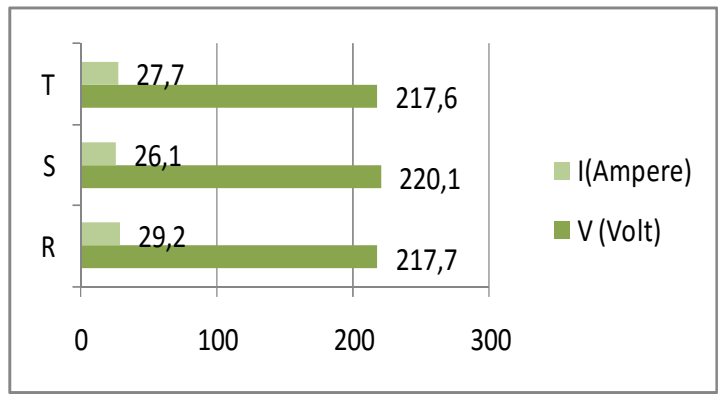

Gambar 18. Pengukuran pada sore hari

\section{Pengukuran pada Gedung Dharma} Penelitian

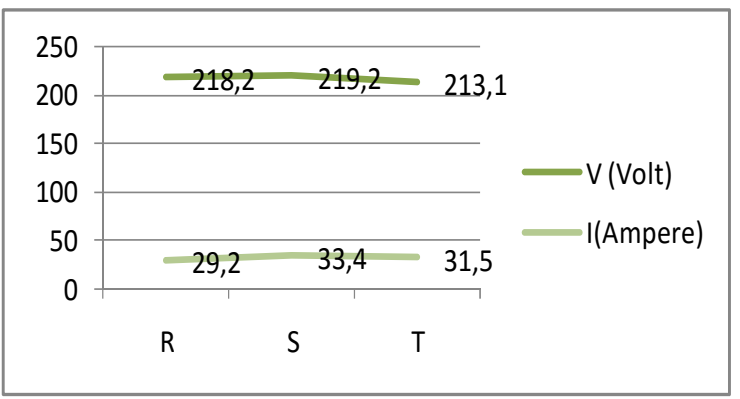

Gambar 19. Pengukuran pada pagi hari

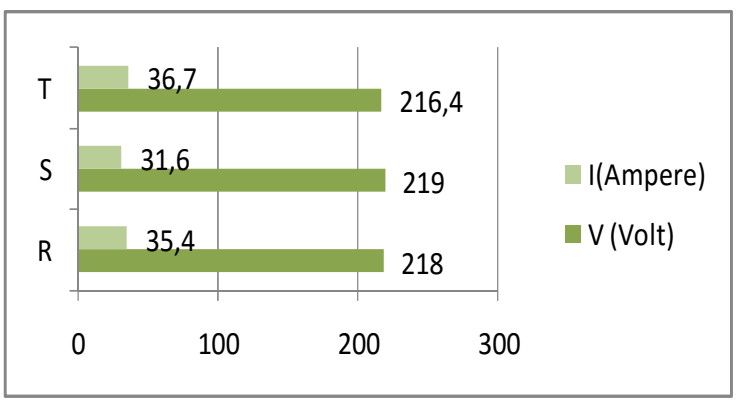

Gambar 20. Pengukuran pada sore hari

\section{J. Pengukuran pada Gedung Dharma} Pengabdian

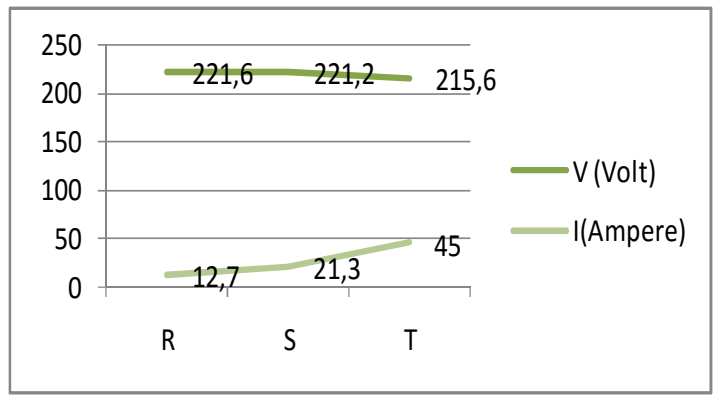

Gambar 21. Pengukuran pada pagi hari 


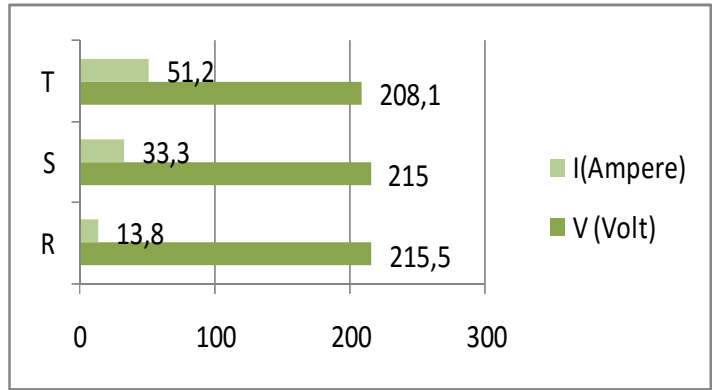

Gambar 22. Pengukuran pada sore hari

\section{K. Pengukuran pada Gedung Teladan}

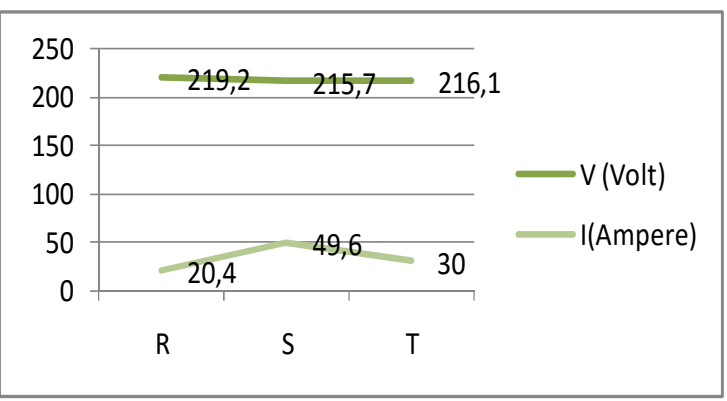

Gambar 23. Pengukuran pada pagi hari

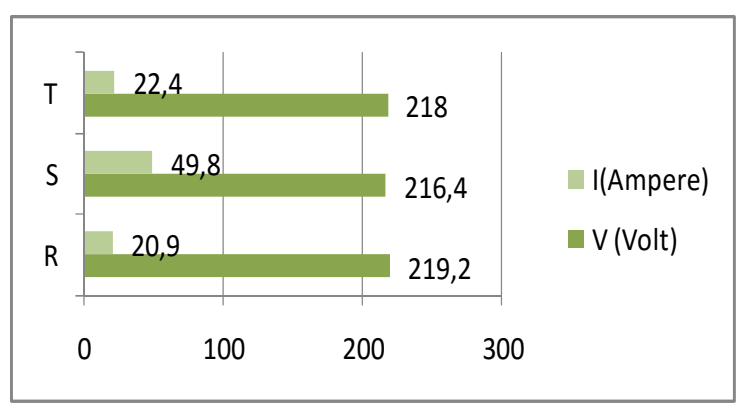

Gambar 24. Pengukuran pada sore hari

\section{Pengukuran pada Gedung Semangat}

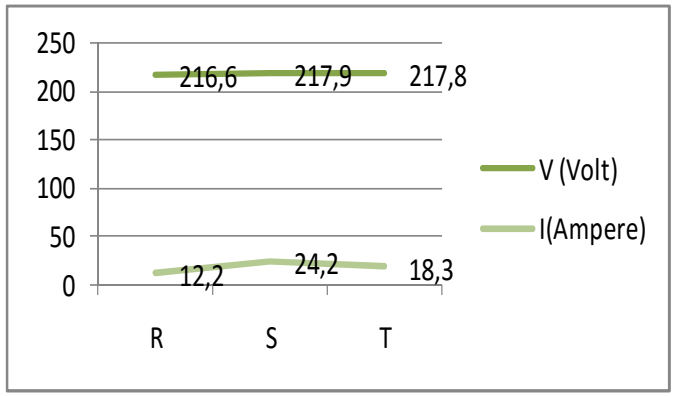

Gambar 25. Pengukuran pada pagi hari

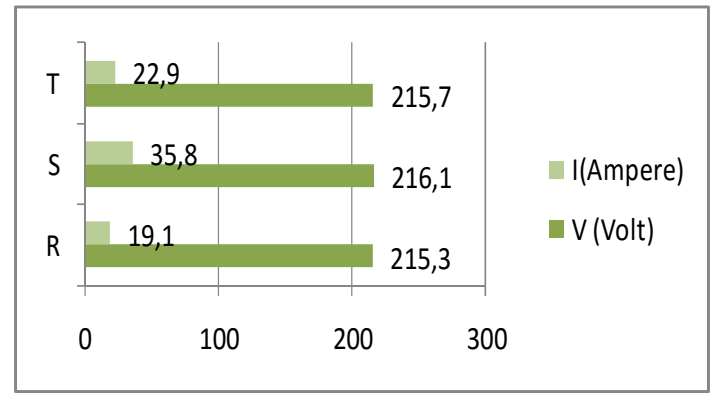

Gambar 26. Pengukuran pada sore hari

\section{Pengukuran pada Gedung Daya}

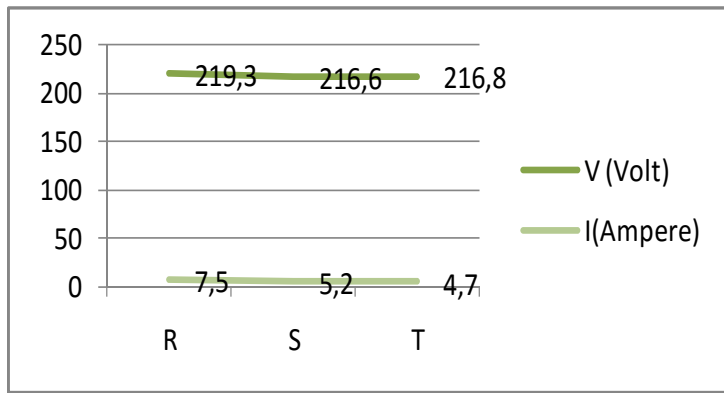

Gambar 27. Pengukuran pada pagi hari

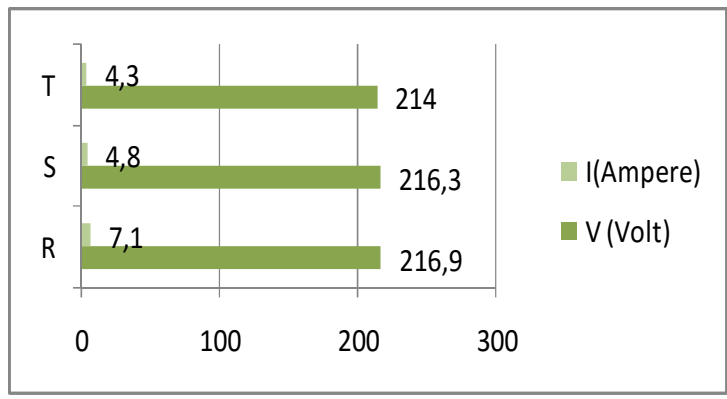

Gambar 28. Pengukuran pada sore hari

Untuk total daya 3 fase dari output trafo distribusi beserta daya 3 fase penggunaan masing-masing gedung pada pengukuran pagi hari (pukul 10.30 WIB), dapat dilihat pada Tabel 1 berikut: 
Tabel 1. Total Daya 3 fase $\left(\boldsymbol{P}_{\mathbf{3}}\right)$

\begin{tabular}{|c|c|c|c|}
\hline & $\begin{array}{c}\text { Arus rerata } \\
\text { (A) }\end{array}$ & $\begin{array}{c}\text { Tegangan } \\
\text { rerata (Volt) }\end{array}$ & $P_{3}(\mathrm{~kW})$ \\
\hline $\begin{array}{c}\text { Output } \\
\text { Trafo } \\
\text { Distribusi }\end{array}$ & 412,8 & 225,8333 & 237,7212 \\
\hline \multicolumn{4}{|l|}{ Penggunaan } \\
\hline Babel I & 36,23 & 229,2333 & 21,180014 \\
\hline Babel II & 28,767 & 226,4667 & 16,612462 \\
\hline Babel III & 24 & 225,8 & 13,81896 \\
\hline Babel IV & 60,767 & 221,3667 & 34,301872 \\
\hline Timah I & 23,167 & 226,433 & 13,376549 \\
\hline Timah II & 21,6 & 226,1 & 12,453588 \\
\hline Pendidikan & 34,1 & 219,033 & 19,046044 \\
\hline Penelitian & 31,367 & 216,833 & 17,343414 \\
\hline Pengabdian & 26,33 & 219,467 & 14,737187 \\
\hline Daya & 5,8 & 217,567 & 3,217811 \\
\hline Semangat & 18,23 & 217,433 & 10,109563 \\
\hline Teladan & 33,33 & 217 & 18,445 \\
\hline \multicolumn{3}{|c|}{ Total penggunaan beban } & 194,6425 \\
\hline
\end{tabular}

Sedangkan total daya 3 fase dari output trafo distribusi beserta daya 3 fase penggunaan masing-masing gedung pada pengukuran sore hari (pukul 14.30 WIB), dapat dilihat pada Tabel 2.

Tabel 2. Total Daya 3 fase $\left(\boldsymbol{P}_{\mathbf{3}}\right)$

\begin{tabular}{cccc}
\hline & $\begin{array}{c}\text { Arus } \\
\text { rerata (A) }\end{array}$ & $\begin{array}{c}\text { Tegangan } \\
\text { rerata } \\
\text { (Volt) }\end{array}$ & $\boldsymbol{P}_{\mathbf{3}} \quad \mathbf{( k W )}$ \\
\hline $\begin{array}{c}\text { Output } \\
\text { Trafo } \\
\text { Distribusi }\end{array}$ & 424,5 & 226,0667 & $\mathbf{2 4 4 , 7 1 1 5 1 5}$ \\
\hline Penggunaan & & & \\
\hline Babel I & 33,23333 & 228,5333 & 19,36705733 \\
\hline Babel II & 18,86667 & 225,1333 & 10,83116467 \\
\hline Babel III & 17,56667 & 211,6667 & 9,481608333 \\
\hline Babel IV & 5,4 & 215,7333 & 2,970648 \\
\hline Timah I & 26,4 & 225,3 & 15,167196 \\
\hline Timah II & 23,76667 & 203,7667 & 12,34927883 \\
\hline Pendidikan & 27,66667 & 218,4667 & 15,41282333 \\
\hline Penelitian & 34,56667 & 217,8 & 19,197981 \\
\hline Pengabdian & 32,76667 & 212,8667 & 17,78607433 \\
\hline Daya & 5,4 & 215,7333 & 2,970648 \\
\hline Semangat & 25,93333 & 215,7 & 14,264241 \\
\hline Teladan & 31,03333 & 217,8667 & 17,24087867 \\
\hline \multicolumn{3}{c}{ Total penggunaan } & $\mathbf{1 5 7 , 0 3 9 6}$ \\
\hline \multicolumn{3}{c}{} &
\end{tabular}

\section{KESIMPULAN}

1. Profil beban berdasarkan pengukuran pada pagi hari (pukul 10.30 WIB), didapatkan bahwa total penggunaan daya 3 fase di Universitas Bangka Belitung sebesar 194,6425 kW.

2. Sedangkan profil beban berdasarkan pengukuran pada sore hari (pukul 14.30 WIB), didapatkan bahwa total penggunaan daya 3 fase di UBB sebesar 154,0396 kW.

\section{DAFTAR PUSTAKA}

[1]. Berahim, Hamzah., 1995.'Diktat Teknik Tenaga Listrik Dasar". Jurusan Teknik Elektro UGM.Yogyakar'ta..

[2]. Wildi,Theodore.,2002."Electrical Machines, Drives and Power Systems 5th ed".Prentice Hall. New Jersey.

[3]. Zuhal, 1986, Dasar Tenaga Listrik, ITB, Bandung. 